\title{
O OUTRO LADO DA HISTÓRIA: A ENTREGA DE UM FILHO PARA ADOÇÃO
}

\author{
THE OTHER SIDE OF THE STORY: DELIVERY OF A CHILD FOR \\ ADOPTION
}

Patrícia Jakeliny Ferreira de Souza Moraes ${ }^{1}$
Benedito Rodrigues dos Santos ${ }^{2}$
Rosimeire Romeiro Rabelo

\section{RESUMO}

O presente artigo analisa a intenção da entrega do filho para adoção de três genitoras. Baseia-se na pesquisa qualitativa de Minayo (2007), com a utilização dos instrumentos observação participante e análise de relatórios sociais. A pesquisa foi realizada no período entre 2009 e 2010, em um Núcleo de Serviço Social de um Hospital Público do Distrito Federal. Revela que o ato da entrega, tende a estar relacionado a ausência de uma rede sócio familiar, a carência econômica e a falta de políticas públicas.

PALAVRAS-CHAVE: Adoção. Abandono. Maternidade. Políticas Públicas.

\section{ABSTRACT}

This paper analyzes the genitor's intention of handing her child to adoption. It is based on Minayo (2007) qualitative research, with the use of the instruments: participant observation and analysis of social reports. The survey was conducted in the period between 2009 and 2010 on a Core Social Work of a Public Hospital Federal District. It reveals that the act of delivery tends to be related to the absence of a social and family network, economic deprivation and lack of public policies.

KEYWORDS: Adoption. Abandonment. Maternity. Public Policies.

\section{INTRODUÇÃO}

A gravidez é uma fase de grandes transformações para a mulher, durante esse período ela se encontra mais vulnerável e propensa a crises devido à ocorrência de mudanças físicas, psicológicas e sociais (LOPES, et al., 2012). O nascimento de um

\footnotetext{
${ }^{1}$ Assistente Social, Un . Mestre em Psicologia, UC . Doutoranda do curso de Psicologia da UC . Telefone 61 34353442, e-mail: ja elin@hotmail.com.

${ }^{2}$ Doutor em Antropologia pela Universidade da Calif rnia, em er ele . Professor da Universidade Cat lica de ras lia e coordenador do Núcleo de Pes uisas da Inf ncia, Adolesc ncia e Fam lia - NIAF da Pr -Reitoria de Pes uisa da UCG. E-mail: enedito.santos.r@gmail.com.

${ }^{3}$ Graduada do curso de Serviço Social da UC .E-mail: romeirora elo@gmail.com. erv. Soc.\& Saúde, Campinas, SP v. 11, n. 2 (14) p. 209-222 jul./ dez. 2012 ISSN 1676-6806
} 
filho requer uma reorganização familiar baseada no apoio de sua rede sócio familiar que preexiste antes do nascimento da criança. Muitas mulheres que abandonam seus filhos ou os colocam à disposição da justiça para adoção, encontram-se à margem da pobreza, desprovidas de condições estruturais (BADINTER, 1985; FORNA, 1999; WEBER, 2004; FONSECA, 2012).

A mulher, antes de abandonar seu filho, já se encontra abandonada e, absolutamente, excluída pela sociedade (SANTOS, 1998; MOTA, 2005). Os fatores que influenciam a entrega de um filho têm origem na ausência de políticas públicas e na desproteção da família (CRISPI, 2007). É preciso desconstruir a imagem da "mãe desnaturada" que não quer ficar com seu filho, entendendo o fato do abandono como uma perspectiva social. Será que as políticas públicas brasileiras, estão contemplando a diversidade da família contemporânea e considerando seus determinantes sócioshistóricos? O que leva uma mãe a optar pela entrega de seu filho? Dentre os possíveis fatores que envolvem essa entrega destaca-se: a exclusão social das famílias, a impossibilidade do aborto legal, o medo de não dar conta dessa maternidade, a falta de apoio sócio familiar, a ausência de um suporte psicossocial (WEBER, 2004).

Alguns estudos desenvolvidos por (FRESTON e FRESTON 1994; CHRISPI, 2007; FÁVERO, VITALE e BAPTISTA, 2008; GIBERTI, 2010) apontam os determinantes sociais: irrisória participação do homem na criação dos filhos, a falta de uma rede familiar consistente, a ausência do genitor e a falta de condições socioeconômicas e emocionais, como os principais responsáveis pela entrega de uma criança para adoção. Diante destas situações de exclusão o Estado se esquiva de suas responsabilidades, não possibilitando a estas mães, políticas sociais básicas, capazes de viabilizar a continuidade de sua maternagem. Tal modelo de minimização do Estado está fundamentado no modelo neoliberal capitalista e contribui para o agravamento das condições sociais dessas mulheres.

Corrobora com esses estudos Fernandes et al (2011) em pesquisa desenvolvida, com 12 mães de prematuros internados no Setor de Neonatologia do Hospital Universitário Materno Infantil do Maranhão, apontando em seus resultados que mães ao falarem sobre seu abandono o fazem a partir de suas histórias de vida, as quais apontam para uma falta de apoio familiar, uma falta de acompanhamento durante o pré-natal, pela tentativa frustrada de aborto e pela ausência de apoio do pai do bebê. Tal dinâmica reproduz o modelo de família monoparental, predominantemente matriarcal. 
Consonante com esses achados, estudos desenvolvidos por Forna (1999) e Santos (1998) apontam o "mito do amor materno", como um grande indicativo desta questão, através de sua constante influência no que tange o julgamento da mulher. Este, por sua vez, garante-lhes a condenação e o isolamento durante e após o processo de entrega da criança para adoção.

Estudos desenvolvidos por Giberti (2010) relatam que mães que entregam seus filhos para adoção, devido a pressão da família, amigos ou da própria situação financeira, são também as que mais empreendem esforços na busca ativa de seu filho em anos posteriores à entrega, ao contrário das mães que mencionam razões como idade, despreparo para a maternidade ou desejo de completar os estudos para sua decisão.

Para Motta (2005), ao contrário do que o imaginário social sustenta, a principal razão para a decisão de entregar um filho em adoção ou a simples ideia de fazê-lo pode estar associado as condições psicossociais da mulher.

Dentro desse contexto complexo, pretende-se com esse artigo discutir os fatores que levam uma mãe biológica a abrir mão do filho para adoção, nossa intenção é enfatizar o momento dessa decisão como um processo passível de intervenção social. Embora alguns estudos abordem a dificuldade de tomada de decisão de algumas mães, estes discutem a temática do ponto de vista do ato já consumado, nossa intenção é avaliar esse processo e os caminhos possíveis de intervenção.

\section{INCURSÃO HISTÓRICA DO ABANDONO DE CRIANÇAS}

$\mathrm{O}$ ato de dispor crianças vem sendo majoritariamente visto como “abandono" (WEBER, 1994/2004; FONSECA 2006/2012; MENEZES, 2007), todavia, essa prática foi difundida e aceita pela sociedade, pelo Estado e pela Igreja Católica até o século XVI. Apenas em meados do século XVII e início do século XVIII o "abandono" de crianças passou a ser uma prática condenada, pois, os maus cuidados e a indiferença em relação à infância faziam com que grande parte das crianças morressem (MALDONADO, 1985/1989).

No Brasil, a valorização da criança só ganhou visibilidade com a industrialização, cuja mão de obra era necessária (RIZZINI, 2008). Os primeiros trabalhos desenvolvidos com crianças no Brasil foram realizados pelos jesuítas e datam 
dos séculos XVI e XVII, onde realizavam catequeses nas chamadas Casa dos Muchachos. Eles reuniam os órfãos para ensinar a ler, escrever e aprender os bons costumes. No século XVIII, aparece o sistema Roda dos Expostos $^{4}$ (FONSECA, 2012) que constituiu a principal política de atendimento às crianças enjeitadas - a infância pobre, em todo o Período Colonial, Imperial e que se estendeu até o Período Republicano.

A Roda dos Expostos era mantida pelas irmandades religiosas e pelas Santas Casas de Misericórdia e se transformaram na principal política social para crianças pobres do Brasil Colonial e Republicano. A miséria era um fator que resultava na desagregação das unidades familiares, pois, as crianças que sobreviviam nas instituições, a partir do século XIX e XX, passaram a ser preparadas com sete anos para o trabalho (RIZZINI, 2008, FONSECA, 2012).

Segundo Chrispi (2007) a função das rodas era conter o aborto e o infanticídio, que até o século XVIII chegava a uma perda de $30 \%$ do número de bebês mortos por fome, sede ou que eram comidos por animais, após serem deixados nas ruas, nas igrejas e conventos. A partir do século XIX a mortalidade infantil passou a ser considerada problema social, demográfico e político. Esses dados mostram o descaso que o Estado tinha em relação às crianças abandonadas e a fragilidade de vínculo apresentada entre a genitora e o filho.

O Código de 1927, estabelecido pelo Decreto n $17.943-A$ de 12 de outubro de 1927 veio para consolidar "as leis de assistência e proteção a menores". Esse decreto aboliu o sistema das rodas, mas manteve seus princípios de preservar o silêncio sobre a origem da criança.

Em 1942, foi criado o Serviço de Assistência ao Menor (SAM), então ligado ao Ministério da Justiça, que era o equivalente ao Sistema Penitenciário para a população de menor idade, com enfoque tipicamente correcional-repressivo. Ainda no governo de Getúlio Vargas foi criada a Legião Brasileira de Assistência (LBA), tendo, depois, se estabelecido como instituição de assistência suplementar para a sociedade civil de modo geral.

\footnotetext{
${ }^{4}$ Dispositivo de madeira onde se deposita o e . De forma cil ndrica e com uma divis ria no meio, esse dispositivo era fi ado no muro ou na janela da instituiç o. No ta uleiro inferior da parte e terna, o e positor colocava a criançinha ue enjeitava, girava a Roda e pu ava um cord o com uma sineta para avisar vigilante ou Rodeira ue um e aca ara de ser a andonado, retirando-se furtivamente do local, sem ser reconhecido ( RIES, 1981).

Serv. Soc. \& Saúde, Campinas, SP v. 11, n. 2 (14) p. 209-222 jul./dez. 2012 ISSN 1676-6806
} 
No ano de 1964 foi estabelecido a Política Nacional de Bem-Estar do Menor (PNBEM), com proposta claramente assistencialista, a ser executada pela Fundação Nacional de Bem-Estar do Menor (FUNABEM). O objetivo era dar um caráter nacional à política de bem-estar de crianças e adolescentes. Ela serviu de órgão aglutinador do planejamento, da gerência e da execução da política de assistência ao "menor" no território brasileiro.

A Lei 6.697, de 10 de outubro de 1979, denominada Código de Menores, deu continuidade ao Código de 1927, acentuando as disposições relativas ao abandono e à delinquência. Havia, no entanto, uma visão mais terapêutica ou de tratamento relativa ao infrator. Entretanto, dentro dos estabelecimentos e no processo de internamento predominava a mesma visão moralista, de inibição dos desvios e de vícios na família ou na sociedade. Na década de 1980, que se caracterizou pelo início da abertura democrática, a legislação e as políticas destinadas aos “menores" passam a ser vistas como representativas do arcabouço autoritário do período anterior.

Neste Código, a declaração da situação irregular não distinguia, com clareza, situações derivadas da conduta pessoal do adolescente, ou seja, infrações por ele praticadas, daquelas que envolviam o seu entorno - como a família, no caso de maus tratos, ou da própria sociedade, nas situações de abandono. Em decorrência disso, surgiram as instituições para "menores", reunindo em um só lugar as crianças consideradas infratoras, abandonadas e vítimas de maus tratos, tendo como pressuposto que todos estariam na mesma condição "irregular". Essas crianças eram vistas como uma "patologia social ou uma anomalia", e eram encaminhadas para essas instituições, as quais representavam uma oportunidade de controle e disciplina (JANCZURA, 2005).

Em 1990, é aprovado o Estatuto da Criança e do Adolescente (ECA), por meio da Lei 8.069 de 13 de julho de 1990, regulamentado pelo artigo 227 da Constituição de 1988, estabelece os direitos fundamentais da criança e do adolescente. Além disso, o Estatuto harmoniza-se com a Convenção sobre os Direitos da Criança e do Adolescente, aprovada pela Assembleia Geral das Nações Unidas em 20 de novembro de 1989. Em decorrência da aprovação do ECA, a FUNABEM foi extinta, tendo sido criada a Fundação Centro Brasileiro para a Infância e a Adolescência (FCBIA), dentro do Ministério da Ação Social, cuja estrutura tinha como objetivo contemplar os novos princípios do estatuto e realizar a ação integrada com as outras esferas de governo. 
Com a implementação da Lei 8.745 em 1993 tanto a FCBIA como a LBA foram extintas. As ações destinadas a proteção das crianças e adolescentes passaram então, ser atribuições tanto da Secretaria de Defesa dos Direitos da Cidadania do Ministério da Justiça como da Secretaria de Assistência Social do Ministério da Previdência e Assistência Social. Dez anos depois, em 2003, foi criada a Secretaria Especial dos Direitos Humanos (SEDH), ligada à Presidência da República. Paralelo a esse processo, em 2004 foi aprovado pelo Conselho Nacional de Assistência Social (CNAS) a Política Nacional de Assistência Social (PNAS), com o objetivo de concretizar direitos assegurados na Constituição Federal e na Lei Orgânica de Assistência Social.

Assim, a Política Nacional de Assistência Social (PNAS, 2004) organiza a matriz de funcionamento do Sistema Único de Assistência Social (SUAS), inaugurando no país um novo paradigma de defesa dos direitos socioassistenciais. Na sequência, a aprovação da NOB/SUAS estabelece parâmetros para operacionalização do SUAS em todo o território nacional (BRASIL, 2005). Em 2006, foi aprovada a Norma Operacional Básica de Recursos Humanos (NOB-RH) do SUAS que, dentre outros aspectos, estabeleceu parâmetros nacionais para a composição das equipes que devem atuar nos serviços de acolhimento (BRASIL, 2009).

Em 2009 é promulgada a Lei 12.010/09, a qual altera a Lei 8.069/90 - ECA. Visando nortear parâmetros de atendimento para a realidade de crianças e adolescentes em sistema de acolhimento institucional no Brasil. Neste mesmo ano, o CNAS juntamente com o Conselho Nacional dos Direitos da Criança e do Adolescente (CONANDA), através da resolução conjunta n. 1, de 18 de junho de 2009, aprovou as orientações técnicas que tem como finalidade regulamentar em todo território nacional os Serviços de Acolhimento para Crianças e Adolescentes, no âmbito da Política de Assistência Social.

No Código Civil Brasileiro e no Estatuto da Criança e do Adolescente (ECA), está claro que a adoção deve priorizar as reais necessidades, interesses e direitos da criança e do adolescente, lembrando também que a adoção representa a oportunidade de exercício da paternidade/maternidade para pais que não puderem ter filhos biológicos ou optaram por ter filhos sem vinculação genética. Todavia ao falarmos dessas famílias também estamos falando de outras que por motivos, muitas vezes, alheios às suas vontades, abrem mão do direito de criarem seus filhos. Essa realidade paradoxal, nos exige um aprofundamento dessa questão. 


\section{AMOR MATERNO: UMA CONSTRUÇÃO SOCIAL}

Essa análise faz-se necessária para entendermos a realidade da mulher em relação ao mito do amor materno entre os séculos XII e XVIII. Durante os séculos XII e $\mathrm{XVI}$ as crianças eram vistas como engraçadinhas e pequenos animaizinhos (ÀRIES, 1981). O sentimento encantador da infância permaneceu limitado a essas características. $\mathrm{Na}$ vida cotidiana, as crianças estavam misturadas com os adultos, e toda reunião para trabalho/passeio/jogo reunia crianças e adultos nos mesmos espaços (BADINTER, 1985, FONSECA, 2012).

As mudanças começam a ocorrer em meados dos séculos no século XVII, quando começavam a usar trajes que as distinguiam dos adultos. Essa mudança mostra a nova relação da sociedade com as crianças. Nesse mesmo contexto, surge um novo sentimento, a "paparicação", em que a criança, por sua ingenuidade, gentileza e graça era fonte de distração e relaxamento para os adultos. Muitos pais só consideravam seus filhos pequenos quando eles proporcionavam diversão e alegria, sentimento esse que surgiu no meio familiar. Durante esse período até meados do XVIII, as crianças não eram vistas como pessoas em desenvolvimento, mas como um mini adulto (ÀRIES, 1981). Muitas mulheres nessa época, que perdiam seus filhos, substituíam essas crianças por outros filhos que nasciam posteriormente (BADINTER, 1985).

Segundo Badinter (2011) no imaginário social o instinto materno deve ser natural a todas as mulheres e está associado a fatores culturais, ideológicos, as condições históricas, sociais e econômicas de cada época. Diferente dos séculos passados, atualmente uma mulher pode optar pela maternidade, porém, quando ela decide em não ser mãe, ela pode ser julgada pela sociedade, como egoístas e desnaturada (MOTA, 2005).

Autores como Giberti (1987/2010) e Chrispi (2007) afirmam que por trás do abandono de crianças há uma violência social, psicológica e simbólica às mulheres, as quais, muitas vezes vivenciam gestações inesperadas ou indesejadas. Em muitas situações essas gravidezes são acompanhadas pela indiferença do seu companheiro e pela falta de apoio de sua família extensa. Essas situações desenham uma paisagem de violências simbólicas que podem levar ao ato da entrega do filho a adoção.

Poderíamos pensar então que o que existe é uma fabulosa pressão social para que a mulher só possa se realizar na maternidade? Como saber se o desejo legítimo da 
maternidade não é um desejo em parte alienado e uma resposta às coerções sociais? Para muitas mulheres, a maternidade é uma dualidade entre procriação e maternagem que é afetada por mitos como o da "boa mãe", e da "mãe sagrada", que lhe exige uma dedicação exclusiva aos filhos (SERRURIER, 1993).

\section{MÉTODO}

A metodologia utilizada para realização dessa pesquisa foi baseada nos pressupostos da pesquisa qualitativa de Minayo (2007), que busca aprofundar os significados das relações, compreendendo a realidade e especificando os atributos do objeto de investigação, pois, consegue captar e compreender o universo dos sujeitos. A técnica utilizada na concretização dessa pesquisa foi à observação participante e a análise de relatórios sociais. A observação participante nos possibilitou uma construção de conhecimento mais objetiva e uma melhor compreensão da realidade. A análise do relatório social teve a finalidade de esclarecer e subsidiar nossa análise teórica. Nos três casos estudados, esses relatórios apontam os determinantes sociais que influenciaram a genitora entregar o filho para adoção.

\section{LOCAL DA PESQUISA}

Esta pesquisa foi realizada em um Núcleo de Assistência Social de um Hospital Público do Distrito Federal, entre o período 2009 a 2010. A partir da observação participante junto a equipe de nove assistentes sociais, cinco agentes sociais e três técnicos administrativos, que realizavam atendimentos para o público em geral do hospital, em todas as clínicas, maternidade, ambulatório, pronto socorro. Através de orientações trabalhistas, previdenciárias ou qualquer outro tipo de necessidade ou encaminhamento apresentada pelos usuários do serviço. Especificamente em relação às gestantes que queriam entregar seu filho para adoção, essa mesma equipe priorizava uma escuta de acolhimento, orientação e encaminhamento para acompanhamento jurídico. 


\section{REDE DE PROTEÇÃO A GESTANTE E A PARTURIENTE QUE DESEJA ENTREGAR O FILHO PARA ADOÇÃO NO DISTRITO FEDERAL}

Nossa análise verificou que a maioria das mulheres gestantes que buscavam o pré-natal ou algum atendimento ginecológico no Hospital pesquisado, o fizeram a partir do Núcleo de Assistência Social. Esses atendimentos perpassaram pela procura de informações sobre como proceder para entrega de seu/sua filho (a) para adoção. Também chegavam a este serviço, parturientes internadas no Centro Obstétrico que externavam seu desejo de entrega do filho a própria equipe de enfermagem ou médica do Hospital.

O Hospital pesquisado através do seu Setor de Serviço Social dispõe de espaço de escuta diferenciado as gestantes que após decidirem pela entrega do filho para adoção são encaminhadas ao programa de Adoção Legal implantado pela Vara da Infância e Juventude. Trata-se de um serviço de acolhimento e orientação às gestantes que não desejam ou têm dificuldades em assumir o filho após o nascimento. Este Programa tem parceria com toda a Rede de Saúde Pública do Distrito Federal, cujo objetivo é proporcionar um ambiente de reflexão e acompanhamento, principalmente durante a gestação.

De acordo com o art. 13, parágrafo único, da Lei 12.010, de 2009 as gestantes ou mães que manifestarem interesse na entrega de seus filhos para adoção devem ser encaminhadas à Vara da Infância e Juventude para que possam receber atendimento específico. Esgotados todos os esforços para manutenção dos vínculos legais e afetivos entre a criança e os familiares, a interrupção definitiva da convivência poderá ser efetivada a partir dos meios legais. Após tomar conhecimento, via relatório, da vontade expressa pela genitora, o juiz avalia e determina ao Posto de Saúde ou ao Hospital mais próximos à residência da gestante um acompanhamento através do prénatal. Ao dar à luz e obter alta hospitalar a genitora, em audiência com o Juiz, Promotor de Justiça e Defensor Público expressa sua intenção de entrega, sendo a criança, então encaminhada para uma família substituta, previamente cadastradas para adoção. Além disso, caso a genitora decida permanecer com a criança, o Juiz pode encaminhá-la para atendimento em programas sociais como o Centro de Referência de Assistência Social (CRAS), o Centro Especializado em Assistência Social (CREAS) ou o Conselho Tutelar. Nos casos de abuso sexual, a gestante poderá ainda receber atendimento no 
Programa Violeta, que se situa dentro do Hospital da Criança e do Adolescente HMIB, ou ser encaminhada para o Adolescentro ou ainda para os Postos de Saúde do Distrito Federal.

\section{CASOS EMBLEMÁTICOS}

CASO 1: $\mathrm{Eva}^{5}, 33$ anos estava na quinta gestação, sendo que seus outros quatro filhos moravam no Estado de Minas Gerais com sua mãe. A participante justificou que recebeu apoio emocional e financeiro durante todo o pré-natal e pós-parto de uma senhora que não teve filhos e que estava interessada em ficar com a criança Em relatos colhidos no prontuário, a genitora deixou registrado que o motivo para entrega se devia a dificuldade financeira que estava vivenciando.

CASO 2: Nina, 28 anos, estava na terceira gestação, sendo que suas outras duas filhas moravam com sua mãe na Bahia. Deixou registrado no prontuário que o pai do seu terceiro filho é também o pai de suas outras duas filhas, as quais paga pensão alimentícia. Porém o mesmo não quis assumir essa paternidade, por isso se encontrava separada dele a cinco meses residindo com a irmã e uma sobrinha de um mês de idade, em uma casa alugada. Segundo a gestante, o que a levou a tomar a decisão da entrega foi sua falta de condições financeiras. Em depoimento mencionou que não quer conhecer o filho, e está desejosa que o mesmo seja entregue com urgência à adoção.

CASO 3: Iris, 14 anos, cursava o $8^{\circ}$ ano do Ensino Fundamental e estava no sexto mês de gestação, proveniente de abuso sexual cometido pelo seu genitor, que praticava o ato há quatro anos. Segundo registros do prontuário, Iris menciona que sua genitora desconhecia o fato e que após ter ciência procurou imediatamente a Delegacia de Polícia para registrar boletim de ocorrência. Ambas procuraram o Serviço Social do Hospital, com o objetivo de entregar a criança para adoção após o nascimento.

\section{DISCUSSÃO DOS CASOS}

Nossa análise se baseou na observação participante e nos dados presentes nos relatórios do hospital. A pergunta principal desde estudo refere-se aos motivos e fatos que sustentam o ato da entrega de um filho à adoção. Para subsidiar essa análise buscouse apoio teórico em estudos desenvolvidos por outros autores como Badinter (1985),

\footnotetext{
5 Todos os nomes utilizados nesse estudo são fictícios, com a intenção de proteger o anonimato das usuárias.

Serv. Soc. \& Saúde, Campinas, SP v. 11, n. 2 (14) p. 209-222 jan./jun. 2012 ISSN 1676-6806
} 
Maldonado (1989) e Serrurier (1993) de que o amor materno não é instintivo, mas sim, proveniente de uma construção sócio histórica, que tem como pano de fundo a expressão de afeto, cuidado e reconhecimento. Questões como a impossibilidades estruturais com enfoque socioeconômico podem ser encontrados em estudo desenvolvido por Mota (2005) e Forna (1999).

Este estudo aponta a partir dos três casos citados acima que fatores como a alta vulnerabilidade socioeconômica e psicológica das gestantes doadoras, intensificada pela fragilidade de vínculos com a família extensa e a omissão paterna são intensificadores para a entrega do filho à adoção.

Dados estatísticos apresentados pela Vara da Infância e Juventude do Distrito Federal em 2009, apontaram que os perfis das mães doadoras variavam entre a faixa etária de mulheres de 20 e 30 anos, solteiras ou separadas, que possuíam outros filhos sob os cuidados de parentes. Outros indicadores sociais como a falta de planejamento, a baixa escolaridade, o histórico de abandono, a violência doméstica e/ou sexual, a total precariedade econômica e a ausência de referência materna e vínculos familiares contribuíam para a entrega do filho à adoção.

Embora, os profissionais do Setor de Serviço Social do Hospital pesquisado, não tenham dados estatísticos sobre a proporção de mulheres que manifestavam intenção de disporem de seus filhos para adoção e as que de fato concretizavam esse ato, eles afirmaram que nem todas as mulheres que expunham esse desejo de entrega o efetivam de fato. Foi constatado nos prontuários do Hospital que muitas mulheres desistiam da entrega, mesmo depois do relatório ter sido enviado a Vara da Infância e Juventude.

\section{CONSIDERAÇÕES FINAIS}

Embora os motivos para o ato de dispor crianças para adoção sejam vistos, na maioria das vezes como decorrentes de determinantes econômicos, os dados levantados por esta pesquisa corroboram com estudos desenvolvidos por Motta (2005); Menezes (2007) e Fonseca (2012), que afirmam que os fatores econômicos, combinados com outros aspectos sociais e psíquicos influenciam no ato da entrega do filho para adoção. Além disso, a inexistência de uma rede social de apoio é o fator que mais contribui para essa decisão. 
Nosso intuito foi provocar uma reflexão crítica sobre o ato da entrega da criança para adoção. Fica evidente, a necessidade da ampliação de serviços especializados nesse campo, já que se trata de um momento de muita angústia para a gestante. Seria leviano de nossa parte, pensarmos esse ato como uma escolha racional e deliberada, uma vez que o apelo à maternagem da mulher, encontra-se fortemente arraigado na nossa cultura e na questão de gênero. Os casos analisados aqui, reiteram a importância de considerarmos os dois lados: mães desprovidas de proteção social e filhos que carecem de cuidados e não tem tempo para esperar a reorganização psíquica e social de suas famílias.

O mito do amor materno contraposto a discriminação às mães que entregam seus filhos em adoção sugerem um trabalho de longo prazo que priorize a intervenção dos profissionais com essas gestantes, não só lhes oferecendo um amparo legal, mas, uma reflexão consciente sobre esses motivos. Entender o que permeia a atitude dessas mães é o ponto de partida para elaboração de políticas, programas e ações voltados para essa dada realidade (FONSECA, 2012).

Não é nossa pretensão esgotar este assunto, faz-se necessário outros estudos que venham a contribuir com o aprofundamento do tema em questão. Muitas dessas mulheres, geralmente, são socialmente consideradas como negligentes e acusadas de não assumirem responsabilidades maternas, quando na verdade, a razão encontra-se em uma dura realidade estrutural que as exclui dos seus direitos de exercer sua maternagem.

\section{REFERÊNCIAS}

ARIES, P. História Social da Criança e da família. Rio de Janeiro: Zahar, 1981.

BADINTER, E. Um Amor conquistado: O mito do amor materno. Tradução de Waltensir Dutra. Rio de Janeiro: Nova Fronteira, 1985.

BRASIL. Leis de assistência e proteção a menores. Decreto n. 17.943-A, de 12 de outubro de 1927. Rio de Janeiro. 1927.

BRASIL. Código de Menores. Lei n. 6.697, de 10 de outubro de 1979. Brasília, 1979.

BRASIL. Constituição da República Federativa do Brasil. 1988. Brasília, DF: 1988.

BRASIL. Estatuto da Criança e do Adolescente. Lei no 8.069, de 13 de julho de 1990. Brasília, DF: 1990.

BRASIL. Lei Orgânica de Assistência Social. Lei $n^{\circ}$ 8.745/93. 7 de dezembro de 1993. Brasília, DF, 08 de dezembro de 1993.

Serv. Soc. \& Saúde, Campinas, SP v. 11, n. 2 (14) p. 209-222 jan./jun. 2012 ISSN 1676-6806 
BRASIL. Lei no 12.010, de 07 de agosto de 2009. Brasília, DF: 2009.

BRASIL. Ministério do Desenvolvimento Social e Combate à Fome (MDS). Conselho Nacional de Assistência Social (CNAS). Política Nacional de Assistência Social (PNAS). Resolução n. 145, de 15 de outubro de 2004. Brasília, 2004.

BRASIL. Ministério do Desenvolvimento Social e Combate à Fome (MDS). Conselho Nacional de Assistência Social (CNAS). Resolução n. 130, de 15 de julho de 2004. Norma Operacional Básica da Assistência Social - NOB/SUAS. Brasília, 2005.

BRASIL. Ministério do Desenvolvimento Social e Combate à Fome. Secretaria Nacional de Assistência Social. Norma Operacional Básica de Recursos Humanos/SUAS. Brasília, 2007.

CHRISPI, L. L. S. Por trás da janela: alguns determinantes sociais do abandono de recém-nascidos. Dissertação (Mestrado em Serviço Social). PUC-SP, 2007. FÁVERO, E. T., VITALE, M. A. F., BAPTISTA, M. V. (Org). Famílias de crianças e adolescentes abrigados: quem são, como vivem, o que pensam o que desejam. São Paulo: Paulus, 2008.

FERNANDES, R. T, LAMY, Z. C., MORSCH, D. FILHO, F. L e COELHO, F. L. Tecendo as teias do abandono: Além das percepções das mães de bebês prematuros. Ciências Saúde Coletiva, Rio de Janeiro, v. 16, n.10, 2011.

FONSECA, C. Da circulação de crianças à adoção internacional: questões de pertencimento e posse. Cadernos Pagu, Campinas, v.26, 2006.

FONSECA, C. Mães “abandonantes": fragmentos de uma história silenciada. Estudos Feministas, Florianópolis, v.20, n.1, 2012.

FORNA, A. Mãe de todos os mitos: como a sociedade modela e reprime as mães. Rio de Janeiro: Ediouro, 1999.

FRESTON, Y. M. B. \& FRESTON, P. A mãe biológica em casos de adoção: Um perfil da Pobreza e do Abandono. In: FREIRE, F. (Org.). Abandono e Adoção: Contribuição para uma cultura da adoção. Curitiba: Terre des Hommes, 1994, p.81-90

GIBERTI, E. Adopción siglo XXI. 1ª ed. Buenos Aires: Sudamericana, 2010.

GIBERTI, E. La adopción. Buenos Aires: Sudamericana, 1987.

JANCZURA, R. Abrigos para adolescentes: lugar social de proteção e construção de sujeitos? Textos \& Contextos, v. 4, n. 1, 2005. 
LOPES, R. de C. S. VIVIAN, L. A. G., OLIVEIRA, D. S de, PEREIRA, C. R. R., PICCININI, C. A. Desafios para a maternidade decorrentes da gestação e do nascimento do segundo filho. In: PICCININI, C. A., ALVARENGA, P. (Org), Maternidade e paternidade em diferentes contextos. São Paulo: Casa do Psicólogo, 2012, p. 295-319.

MALDONADO, T. P. Psicologia da Gravidez: parto e puerpério. $7^{\text {a }}$ ed. Petrópolis: Vozes, 1985.

MALDONADO, T. P. Maternidade e Paternidade. Petrópolis: Vozes, 1989.

MENEZES, K. F. L. de. Discurso de Mães Doadoras: Motivos e Sentimentos Subjacentes a Adoção. (Dissertação de Mestrado, Psicologia Clínica). Universidade Católica de Pernambuco, 2007.

MINAYO, M. C. de S. (Org.). Pesquisa Social: Teoria, Método e Criatividade. $26^{\text {a }}$ ed. Petrópolis: Vozes, 2007

MOTTA, M. A. P. Mães abandonadas: a entrega de um filho em adoção. 2 ed. São Paulo: Cortez, 2005.

RIZZINI, I. O Século perdido: Raízes históricas das Políticas Públicas para Infância no Brasil. São Paulo, Cortez, 2008.

SANTOS, S. L. Adoção: da maternidade à maternagem: uma crítica ao mito do amor materno. Revista de Serviço Social, n. 57. São Paulo: Cortez, 1998, p. 99-108.

SERRURIER, C. Elogio às mães más. São Paulo: Summus, 1993.

WEBER, L. N. D. Abandono e Institucionalização de crianças no Paraná. In: FREIRE, F. Abandono e adoção: contribuições para uma cultura da adoção. Rio de Janeiro: Terra dos Homens, 1994, p. 31-46.

WEBER, L. N. D. Laços de Ternura: Pesquisas e histórias de adoção. $3^{\text {a }}$ ed. Curitiba: Juruá, 2004. 